\title{
Buprenorphine Hydrochloride
}

National Cancer Institute

\section{Source}

National Cancer Institute. Buprenorphine Hydrochloride. NCI Thesaurus. Code C47424.

The hydrochloride salt form of buprenorphine, a synthetic phenanthrene with narcotic analgesic activity. Buprenorphine hydrochloride is a partial agonist at the mu-opioid receptor and an antagonist at the kapa-opioid receptor in the central nervous system. However, under the conditions of recommended use it behaves as a classic mu-opioid agonist, mimicking the actions of endogenous peptides at CNS opioid receptors. The agonist action results in a raised pain threshold and increased tolerance to pain. However, it also causes sedation, physical dependence, and respiratory depressant effects and decreases heart rate and blood pressure. 